NASA Technical Memorandum 103202

AIAA-90-1894

\title{
Mars In Situ Propellants: Carbon Monoxide and Oxygen Ignition Experiments
}

Diane L. Linne

National Aeronautics and Space Administration

Lewis Research Center

Cleveland, Ohio

James Roncace

Sverdrup Technology, Inc.

Lewis Research Center Group

Brook Park, Ohio

and

Mary F. Groth

National Aeronautics and Space Administration

Lewis Research Center

Cleveland, Ohio

Prepared for the

26th Joint Propulsion Conference

cosponsored by the AIAA, SAE, ASME, and ASEE

Orlando, Florida, July 16-18, 1990

\section{N/Sh}




\title{
MARS IN SITU PROPELLANTS: CARBON MONOXIDE AND OXYGEN IGNITION EXPERIMENTS
}

\author{
Diane L. Linne \\ National Aeronautics and Space Administration \\ Lewis Research Center \\ Cleveland, $\mathrm{OH} 44135$ \\ James Roncace \\ Sverdrup Technology, Inc. \\ Lewis Research Center Group \\ Brook Park, OH 44142 \\ and \\ Mary F. Groth \\ National Aeronautics and Space Administration \\ Lewis Research Center \\ Cleveland, $\mathrm{OH} 44135$
}

\section{Abstract}

Carbon monoxide and oxygen were tested in a standard spark-torch igniter to identify the ignition characteristics of this potential Mars in situ propellant combination. The ignition profiles were determined as functions of mixture ratio, amount of hydrogen added to the carbon monoxide, and oxygen inlet temperature. The experiments indicated that the carbon monoxide and oxygen combination must have small amounts of hydrogen present to initiate reaction. Once the reaction was started, the combustion continued without the presence of hydrogen. A mixture ratio range was identified where ignition occurred, and this range varied with the oxygen inlet temperature.

\section{Introduction}

Ever since Neil Armstrong took one small step on the surface of the moon, and perhaps even before, the Earth-bound human race has turned its collective eyes toward the planet Mars as the next goal for a race of beings that thrives on challenges. With the objective in mind of first exploring, and then settling on this intriguing red planet, a myriad of ideas, technologies, schedules, options, and philosophies have emerged for the "best" plan to accomplishing this very ambitious goal. Among all of the current frenzy of activity, one idea has continued to arise that is accepted as a general truth. The settlement of Mars in the $21 \mathrm{st}$ century must follow the example of the settlement of the "new world" in the 18th and 19th century; the pioneers needed to establish selfsufficiency or they would not have made it past the Appalachian Mountains.

One necessity for the exploration of any new land is the development of a proper means of transportation. Any mode of transportation needs fuel to sustain it. The early American pioneers needed food and water for their horses, mules, and oxen. We use gasoline today in our automobiles, and the various transportation vehicles used in the settlement of Mars will need fuel and oxidizer propellants. One of the most widely used rocket propellant combinations, hydrogen and oxygen, will not meet the goal of self-sufficiency because there is little or no hydrogen present on the Martian surface or in the atmosphere. The Martian atmosphere is comprised of approximately 95 percent carbon dioxide $\left(\mathrm{CO}_{2}\right)$, which can be dissociated into carbon monoxide $(\mathrm{CO})$ and oxygen $\left(\mathrm{O}_{2}\right)$ for use as propellants. Many individuals have examined the potential benefits obtained when using $\mathrm{CO} / \mathrm{O}_{2}$ for rocket engines for various transportation requirements. These include surface exploration with a ballistic 
hopper or airplane (refs. 1-2), manned and unmanned ascent/descent (ref. 3), and Earth return transportation (refs. 4-5).

The burning of carbon monoxide and oxygen has been accomplished in many applications, such as shock tubes and flat flame burners. One common example of the burning of carbon monoxide occurs in the catalytic converter in a standard automobile. Here, $\mathrm{CO}$ products from the incomplete combustion of the hydrocarbons are oxidized by the oxygen present in the air, with the aid of a catalyst. The catalyst is needed to lower the activation energy of the reaction and allow it to proceed to completion at the temperatures and pressures present in the engine.

Theoretical predictions from a chemical equilibrium computer code (ref. 6) indicate that the propellant combination of carbon monoxide and oxygen will provide a modest performance in terms of ideal specific impulse. No experiments have been conducted to test the performance of carbon monoxide and oxygen in a typical rocket engine. Many fundamental questions need to be resolved before an operating rocket engine can be developed. These questions concern the ignition of "dry" carbon monoxide, the slow kinetics of the system, the possibility of high dissociation rates, potential cooling methods, and combustion stability.

An experimental program was conducted at NASA Lewis Research Center to investigate the ignition of dry $\mathrm{CO}$ and the affects of the slow kinetic reaction rates of the system. The ignition characteristics of carbon monoxide and oxygen in a standard spark-torch igniter were studied. The ignition boundaries as a function of mixture ratio and hydrogen content were determined for various inlet propellant temperatures.

\section{Background}

The balanced equation for the carbon monoxide oxidation is written as

$$
\mathrm{CO}+\frac{1}{2} \mathrm{O}_{2} \rightarrow \mathrm{CO}_{2}
$$

This reaction, however, has a high activation energy, and therefore a slow reaction rate. A one-dimensional kinetics computer simulation (ref. 7) indicates that at the high temperatures and pressures that would typically exist in a rocket engine chamber that was burning $\mathrm{CO}$ and $\mathrm{O}_{2}$, the energy barrier would be overcome, and the reaction would be self-sustaining. Therefore, in order for $\mathrm{CO}$ and $\mathrm{O}_{2}$ to be an effective propellant combination, an ignition method must be developed to initiate and nurture the reaction until it becomes self-sustaining. This is typical of any non-hypergolic propellant combination. The unusually high activation energy of the carbon monoxide and oxygen system, however, may require more than the use of a spark to initiate ignition. Instead, an alternative method, or a combination of methods, may be required.

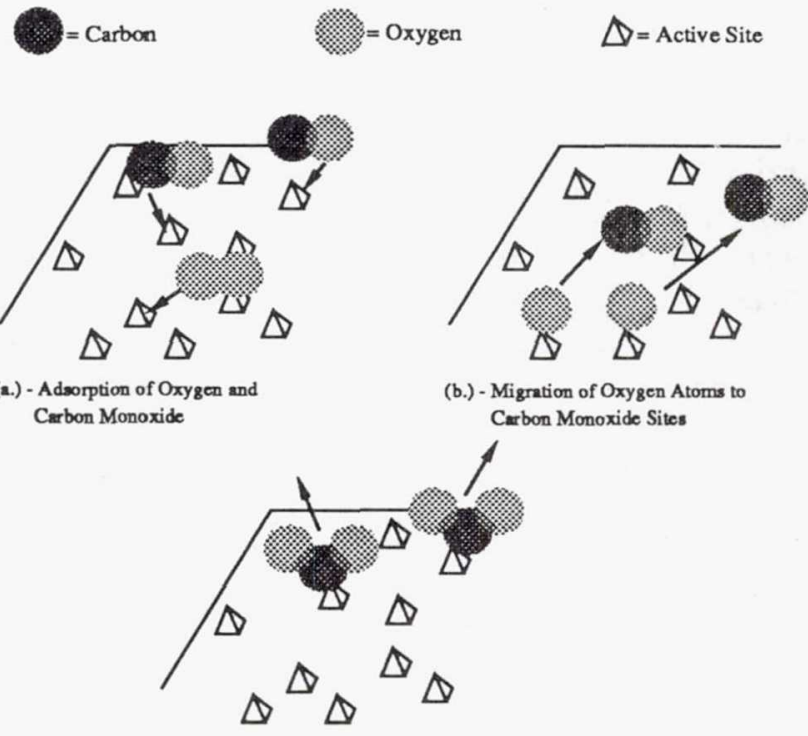

(c.) - Desorption of Carbon Dioxide

Figure 1. Reaction Mechanism with Solid Catalyst.

One method of lowering the activation energy of a reaction is by the introduction of a catalyst to the system. Some transition metal and noble metal catalysts are known to promote the reaction, and are used in the automotive catalytic converter (ref. 8). In this case, the solid catalyst attracts the oxygen molecule $(\mathrm{O}=\mathrm{O})$ and weakens the oxygen double bond (fig. 1a). The carbon monoxide molecules are 
also adsorbed onto the catalyst. Once the bond is broken, the individual oxygen atoms are free to move about the catalyst (fig. 1b). When an oxygen atom finds a $\mathrm{CO}$ molecule and attaches itself to form carbon dioxide, the catalyst's hold on the new carbon dioxide molecule is weakened, and the molecule is desorbed (fig. 1c). When both oxygen atoms have found a carbon monoxide molecule, the active site on the catalyst is free to attract another oxygen molecule and repeat the process.

The presence of small amounts of hydrogen in the system will also act as a catalyst. The key reactions in the mechanism are listed below.

$$
\begin{aligned}
& \frac{1}{2} \mathrm{H}_{2}+\frac{1}{2} \mathrm{O}_{2} \rightarrow \mathrm{OH} \\
& \mathrm{CO}+\mathrm{OH} \rightarrow \mathrm{CO}_{2}+\mathrm{H} \\
& \mathrm{H}+\mathrm{H} \rightarrow \mathrm{H}_{2}
\end{aligned}
$$

In this case, the hydrogen will attract the oxygen molecule, break the double bond, and form the hydroxyl radical $(\mathrm{OH})$. The carbon monoxide molecule then collides with the hydroxyl radical and obtains the needed oxygen atom. The leftover hydrogen atom will combine with another hydrogen atom to reform molecular hydrogen. Therefore, hydrogen is said to act as a catalyst because it enters and leaves the reaction in the same form.

The tests in this experimental program concentrated on the use of small amounts of hydrogen as the catalyst for the reaction. Once ignition was initiated, the hydrogen was no longer needed, and the reaction was allowed to proceed as a dry system.

\section{Test Apparatus and Procedure}

\section{Test Facility}

The experimental tests for this study were performed in Cell 21 of the Rocket Lab at the NASA Lewis Research Center. This facility contains a low thrust rocket engine test stand with supporting fluid systems that allow precise flow of several fuel and oxidizer combinations. Specific to this research program, the fuel flow systems were configured to supply gaseous carbon monoxide and gaseous hydrogen to the fuel inlet of the igniter hardware. Gaseous oxygen was supplied to the oxidizer inlet of the igniter. Four separate propellant lines were used: two oxygen supply lines (primary and secondary), one carbon monoxide supply line, and one hydrogen supply line. A schematic of the fluid handling system is shown in figure 2. The primary oxygen feed line passed through a liquid nitrogen heat exchanger bath where the flow of oxygen in the line was chilled to temperatures as low as $95 \mathrm{~K} \quad\left(\begin{array}{ll}170 & \mathrm{R}\end{array}\right)$. Downstream of the heat exchanger, ambient temperature oxygen gas from the secondary oxygen line was combined with the chilled flow in the primary line. The mixture of chilled and ambient temperature gases was allowed to reach a uniform, steady temperature as it was transported to the igniter hardware. By adjusting the ratio of flow rates of the chilled and ambient temperature gases, the final oxygen inlet temperature was varied while the total oxygen flow rate was maintained at a constant level. The gaseous hydrogen and gaseous carbon monoxide flows were also combined and allowed to mix prior to injection into the igniter body.

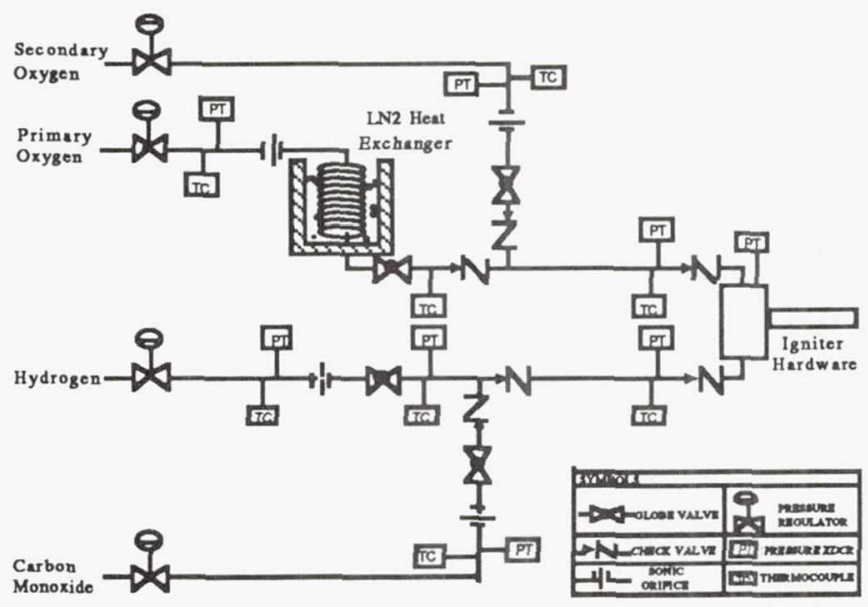

Figure 2. Fluid Handling System.

The flow rate of each of the gases in the system described above was controlled with a sonic orifice. Inserted as a component of the propellant line, each orifice insured a constant flow rate of gas, independent of downstream pressure perturbations. By measuring the line 
pressure and temperature at a point just upstream of each sonic orifice, and using the existing orifice calibration curves, gas flow rates were calculated. Different diameter orifices could be easily interchanged in the system so that the gas flow rate range could be varied throughout the test program. Table I lists the flow rates of each propellant used throughout the experiment.

Table I. Propellant Flow Rates

\begin{tabular}{|l|c|}
\hline Propellant & $\begin{array}{c}\text { Mass Flow Rate } \\
\text { g m/sec } \\
(1 \mathrm{bm} / \mathrm{sec})\end{array}$ \\
\hline \hline Oxygen & $\begin{array}{c}0.798-7.48 \\
(0.00176-0.0165)\end{array}$ \\
Carbon & $1.36-8.34$ \\
Monoxide & $(0.00299-0.0184)$ \\
Hydrogen & $0.0059-0.061$ \\
& $(0.0000130-0.000136)$ \\
Total Flow & 9.07 \\
& $(0.0200)$ \\
\hline
\end{tabular}

\section{Data Acquisition}

Approximately 25 data channels were monitored during the test program. Pressure transducers and thermocouples were used to measure parameters required for gas flow rate calculations. A pressure transducer located on the combustion chamber of the igniter hardware was monitored to verify the flow of oxygen and fuel into the chamber and to determine if combustion occurred when the ignition spark was initiated. Nominal steady-state ignition pressure was $830 \mathrm{kPa}$ (120 psia).

A high speed data acquisition system sequentially scanned the data channels at a rate of 100 samples per second per channel. The raw data signals went through an analog-to-digital converter and were stored on a temporary magnetic storage device. Following the test run, the data was downloaded to a mainframe computer where it was time averaged in tenth of a second increments and permanently stored for post-test analysis.

Eight of the more critical data channels, such as the injection pressure of fuel and oxygen and the chamber pressure of the igniter, were monitored using a high speed chart recorder. In this way, each test run could be immediately analyzed to determine if ignition had occurred and if combustion of the carbon monoxide sustained past the shutdown of gaseous hydrogen flow and ignition spark.

\section{Test Hardware}

Spark-torch igniter hardware was used for the ignition tests. This consisted of a $1.905-\mathrm{cm} \quad(0.75-\mathrm{inch})$ diameter chamber with a $0.358-\mathrm{cm}(0.141$-inch $)$ diameter exit tube. The oxygen and fuel entered the igniter chamber through opposing inlets in the chamber wall. A coolant sleeve covered the exit tube, and gaseous nitrogen flowed through the coolant passage to prevent melting of the tube. Figure 3 shows the hardware on the test stand during a test run.

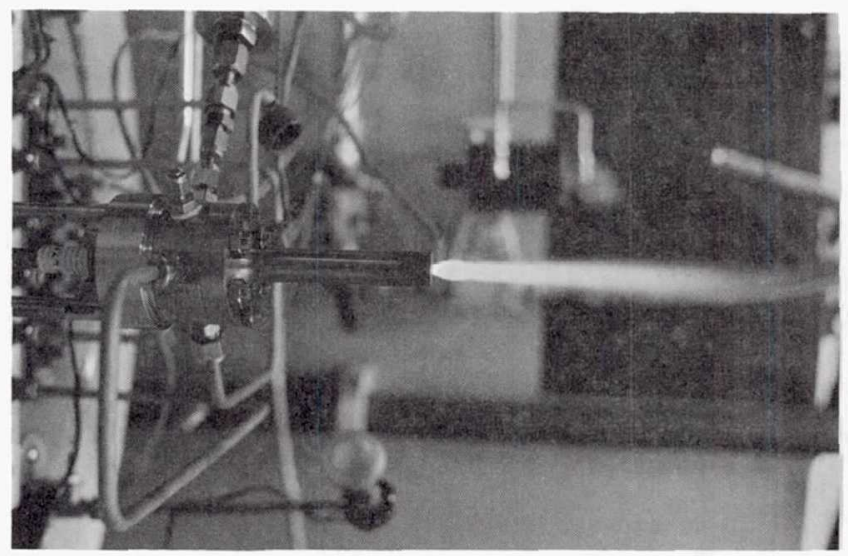

Figure 3. Spark Torch Igniter During Test.

\section{Carbon Monoxide}

The carbon monoxide was contained in $\mathrm{K}$-bottles that were located outside the test cell. In an effort to obtain a very dry (no hydrogen or water) batch of carbon monoxide, a purity grade of 99.9 percent was ordered. A chemical analysis of the carbon monoxide gas indicated that hydrogen and 
water were present in quantities of $5 \mathrm{ppm}$ and $30 \mathrm{ppm}$, respectively. This is equivalent to 3.9 E-5 weight percent of hydrogen and 4.8 E-5 weight percent of water in the carbon monoxide gas.

\section{Test Procedure}

To insure a uniform run profile throughout the duration of the test program, each firing of the igniter was sequenced by a programmable line controller (PLC). After the desired gas flow rates were set by adjusting the pressures upstream of the sonic orifices, the PLC was initiated and the flow of fuel, oxygen, and nitrogen purge gases, as well as the ignition spark, were automatically sequenced in a pre-programmed pattern. The PLC used for these experiments had an accuracy of \pm 0.020 seconds.

Because the boiling point of nitrogen is slightly lower than the boiling point of oxygen, the liquid nitrogen in the heat exchanger caused the gaseous oxygen in the coil to condense between runs. To insure a steady-state flow of gaseous, not liquid, oxygen during the test, each test was started with an oxygen pre-flow. The hydrogen flow was started with the oxygen flow to allow adequate time for the small flow rate of hydrogen to reach steady-state. After 10 seconds of oxygen and hydrogen pre-flow, the carbon monoxide fire valve was opened. Two seconds later, the spark was turned on for 1.2 seconds. The hydrogen flow was shut down 0.5 second after the spark started. The main oxygen and fuel continued for 1.3 seconds after the spark was shut off. Figure 4 depicts the timing just described. The purpose of this timing was to have hydrogen flowing into the igniter when the spark started to initiate reaction, and then to stop the flow of hydrogen to determine if the reaction was self-sustaining.

Three parameters were controlled to investigate the effects on the ignition characteristics. The first was the oxygento-fuel mixture ratio. The mixture ratio was varied from 0.10 to 5.5. The stoichiometric mixture ratio of the oxygen and carbon monoxide reaction is 0.571 .

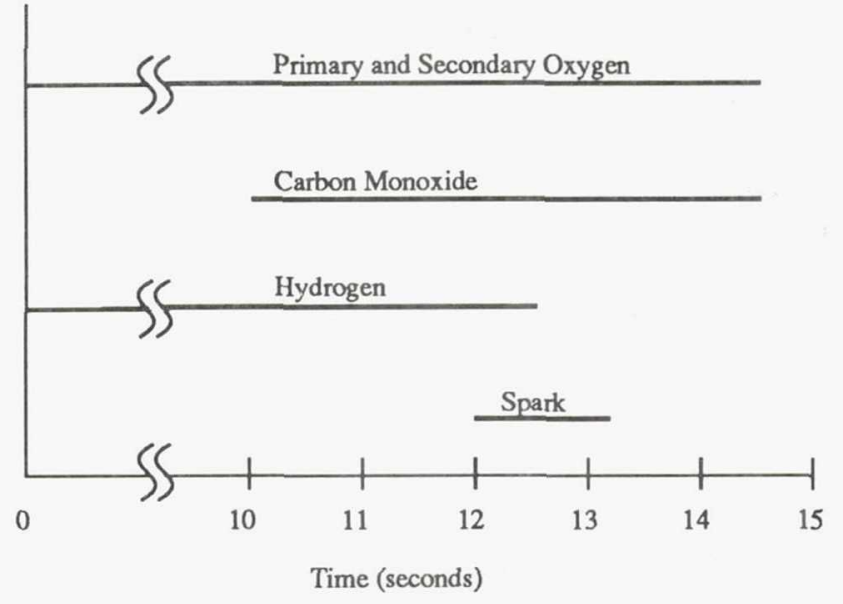

Figure 4. Timing of Propellants and Spark.

The second parameter that was varied was the amount of hydrogen that was added to the carbon monoxide to catalyze the ignition process. The amount of hydrogen was calculated as a weight percent of the carbon monoxide flow rate. The hydrogen flow was varied from 0 to 1.1 weight percent of the carbon monoxide flow.

The inlet temperature of the oxygen was the third parameter that was varied. Although it was difficult to control the oxygen inlet temperature with a great deal of accuracy, four different temperature ranges were obtained by changing the amount of oxygen that flowed through the heat exchanger. The mixture ratio and hydrogen percent variations were performed with 0,25 percent, 50 percent, and 75 percent of the oxygen flowing through the heat exchanger for successively lower oxygen inlet temperatures. The four oxygen inlet temperatures achieved with this method were nominally $292 \mathrm{~K}\left(65^{\circ} \mathrm{F}\right), 255 \mathrm{~K}\left(0^{\circ} \mathrm{F}\right)$, $172 \mathrm{~K}\left(-150{ }^{\circ} \mathrm{F}\right)$, and $105 \mathrm{~K}\left(-270^{\circ} \mathrm{F}\right)$, respectively.

\section{Results and Discussion}

The purpose of the experimental program was to identify the ignition boundaries of the oxygen and carbon monoxide combination as a function of mixture ratio, hydrogen percent, and oxygen inlet temperature. During the testing, it became apparent that some tests 
could not be classified as either ignition or no-ignition, but were somewhere between those two absolutes. Five classifications of reaction were defined. These five classifications and their definitions are as follows:

No Ignition. No reaction was identified by means of sound of combustion, visible plume, or pressure rise in the igniter chamber.

Weak Reaction. A small, unsteady, pressure rise indicated on the chart recorder. This category was characterized by some sounds of combustion from the igniter chamber and a faint, sporadic visible plume.

Half Ignition. Plume was visible during test. Significant, continual pressure rise indicated on the chart recorder. This category was characterized by reactions only during spark activity. This indicated that the ignition process was initiated but was not able to sustain without an external energy source.

Early Shutdown. Plume was visible during test. Pressure rise on chart recorder started to reach steady-state. This category was characterized by reactions that continued after the spark shutdown, but ended before the oxygen and fuel flows were shut off.

Ignition. Solid ignition sustained until the oxygen and fuel flows were shut off. This category was characterized by a strong, steady visible plume, and the attainment of a steadystate pressure.

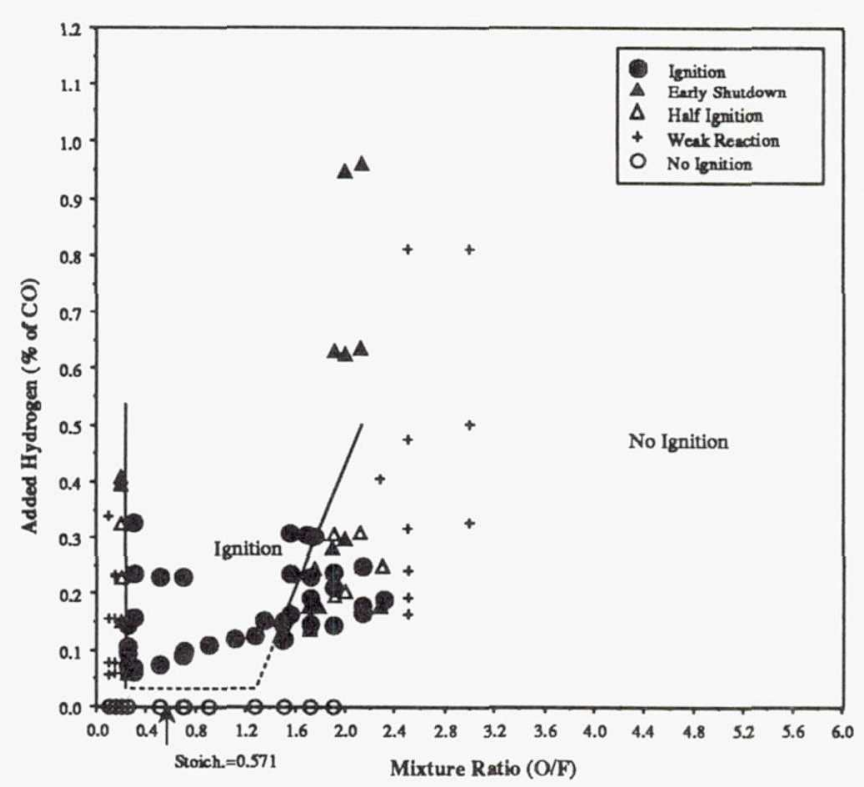

Figure 5. $\mathrm{CO} / \mathrm{O}_{2}$ Ignition Profile. Oxygen Inlet Temperature: $292 \mathrm{~K}\left(65^{\circ} \mathrm{F}\right)$.

\section{Mixture Ratio and Hydrogen Variations}

The mixture ratio and hydrogen percent of fuel were varied to identify the ignition boundaries for the oxygen and carbon monoxide. Figure 5 shows the results from these tests with the inlet oxygen gas at an ambient temperature of $292 \mathrm{~K}\left(65^{\circ} \mathrm{F}\right)$. The mixture ratios shown on the $x$-axis are the ratio of oxygen to carbon monoxide. They do not include the hydrogen in the fuel mass flow rates because the hydrogen flow rates were very small as compared to the carbon monoxide flow rates. In the figure, the darkened circles indicate all conditions where full ignition occurred. The open circles indicate all conditions where no ignition occurred. The other symbols, as defined on the graph, indicate conditions where either a weak reaction, half ignition, or early shutdown occurred. Because a sonic orifice was used in the hydrogen line to measure and control the flow rate, the minimum amount of hydrogen flow rate was limited by the smallest orifice available. This minimum limit on the hydrogen flow rate is the cause of the upward sloping line that could be drawn through the lowest points (other than the zero percent hydrogen points). Although the minimum hydrogen flow rate was a constant at $0.0287 \mathrm{gm} / \mathrm{sec}(1.30 \mathrm{E}-5$ 
$\mathrm{lbm} / \mathrm{sec}$ ), the minimum hydrogen amount, as a percent of $\mathrm{CO}$, increased as mixture ratio increased.

The figure shows an abrupt lower ignition boundary at a mixture ratio of approximately 0.35 . This is indicated by the solid, near-vertical line on the graph. Below this mixture ratio, no complete ignition occurred. The upper ignition boundary is more difficult to identify, as the ignition characteristics proved to be more inconsistent at the higher mixture ratios. In general, below a mixture ratio of 1.5 , ignition occurred consistently, while above this mixture ratio ignition was not guaranteed. Finally, above a mixture ratio of approximately 2.4 , complete ignition was not obtained at any of the conditions tested.

Because of the limit on the minimum hydrogen flow rate, it was not possible to identify the absolute minimum amount of hydrogen needed for ignition. Within the mixture ratio range of 0.35 to 1.5 , ignition occurred whenever the minimum amount of hydrogen flow rate was present. When the same oxygen to carbon monoxide mixture ratios were tested with no added hydrogen, no ignition occurred. This indicates that while the amount of hydrogen needed to initiate reaction is small, it is still greater than the amount of hydrogen that was present in the carbon monoxide gas as impurities. Therefore, the amount of hydrogen needed for ignition in this hardware at a mixture ratio of 0.35 was between 4.4 E-5 weight percent and 6.2 E-2 weight percent. The uncertainty in minimum required hydrogen is indicated by the dashed lines in figure 5 .

It was originally expected that the transition from ignition to no ignition would be gradual, where at the very low or very high mixture ratios ignition could still be achieved if a larger fraction of hydrogen was present. The ignition boundaries shown in figure 5 do not show any indication that this trend exists. There is evidence at the oxygen-rich boundary, however, of a gradual transition from ignition to no ignition. The figure shows that the results of the experiment progress gradually from ignition, to an early shutdown, to a half ignition, to a weak reaction. Even at a mixture ratio of 3.0 , which was the highest one tested at this temperature, there was still some reaction in the igniter chamber. Although the original experimental goal was to identify the mixture ratios where no ignition occurred, the existence of the partial ignitions changed the direction slightly. The new experimental goal was to identify the mixture ratios where complete ignition ceased. For example, figure 5 shows that while complete ignition occurred at mixture ratios below 1.5, and was occasionally obtained up to a mixture ratio of 2.4 , only partial ignitions resulted from tests at mixture ratios of 2.5 through 3.0. This was considered sufficient data for a firm determination of the useful upper ignition boundary at 1.5 , and no tests were conducted at higher mixture ratios.

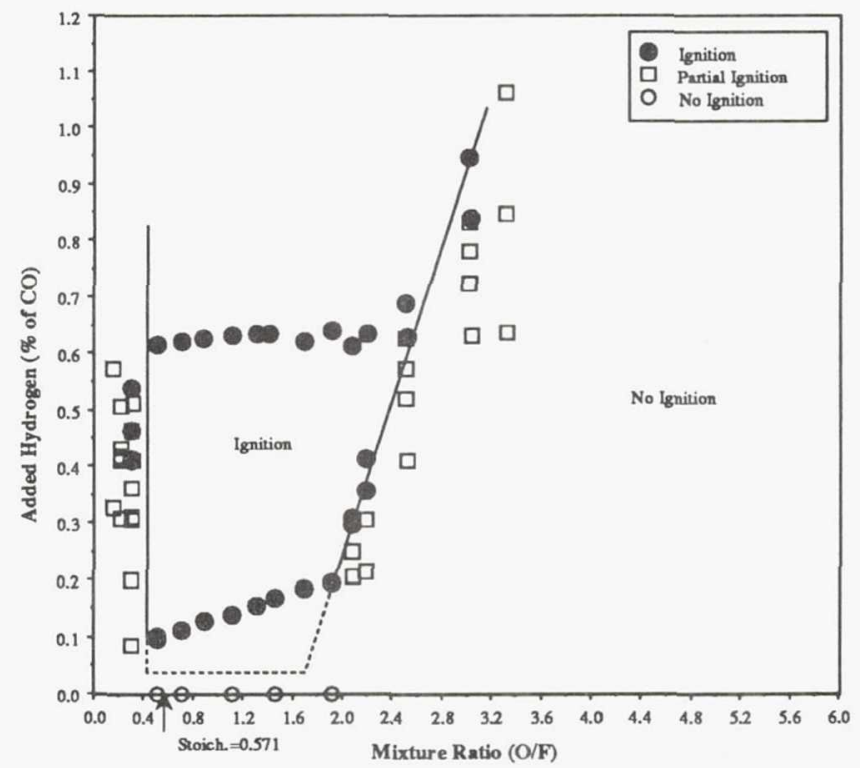

Figure 6. $\mathrm{CO} / \mathrm{O}_{2}$ Ignition Profile. Oxygen Inlet Temperature: $255 \mathrm{~K}\left(0^{\circ} \mathrm{F}\right)$.

The mixture ratio and hydrogen variations were repeated with some of the oxygen flowing through the heat exchanger to lower the inlet temperature of the oxygen. Figures 6 through 8 show the ignition characteristics for successively lower oxygen inlet temperatures. For clarity, the conditions where either a weak reaction, half ignition, or early shutdown occurred were considered partial ignition 
results, and are indicated with an open square. Examining figure 6 , an abrupt ignition boundary can again be seen at the lower mixture ratios. The ignition boundary at the higher mixture ratios, however, exhibits a transition where additional hydrogen was needed to achieve complete ignition. At a mixture ratio of approximately 1.9 , the minimum amount of hydrogen (approximately 0.16 percent) was needed to achieve full ignition. As the mixture ratio increased from this point, the amount of hydrogen needed to initiate the reaction increased. At a mixture ratio of 2.1, 0.30 percent hydrogen was needed in the carbon monoxide. At a mixture ratio of 2.2 , 0.35 percent hydrogen was needed. This trend continued to a mixture ratio of 2.9 , where 0.85 percent hydrogen in the carbon monoxide was needed to initiate ignition. This trend could be expected to continue past that shown on the graph, as no hydrogen amounts greater than 1.2 percent were tested in this program.

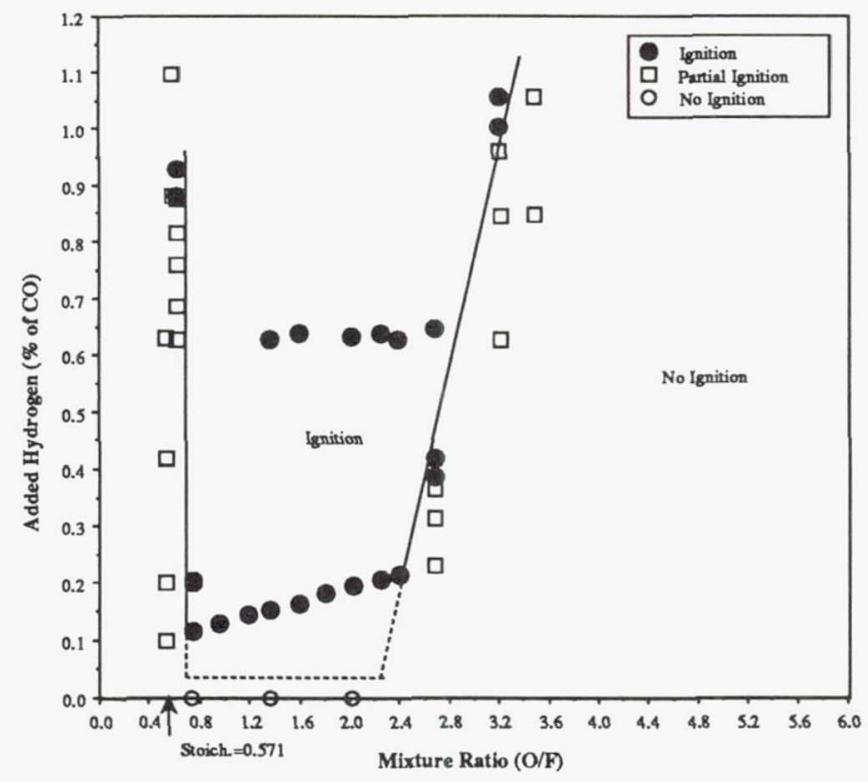

Figure 7. $\mathrm{CO} / \mathrm{O}_{2}$ Ignition Profile. Oxygen Inlet Temperature: $172 \mathrm{~K}(-150$ $\left.{ }^{\circ} \mathrm{F}\right)$.

The ignition boundaries in figure 7 , where the oxygen inlet temperature was approximately $172 \mathrm{~K}\left(-150{ }^{\circ} \mathrm{F}\right)$, show the same trends as those in figure 6. That is, the lower ignition boundary is abrupt, and the upper ignition boundary shows a gradual transition. The ignition boundaries in figure 8 , where the inlet oxygen temperature was approximately $105 \mathrm{~K}(-270$ $\left.{ }^{\circ} \mathrm{F}\right)$, exhibit an abrupt boundary at both the lower and upper mixture ratios. The results at this temperature are also different from the other temperatures tested in that there is a more narrow ignition range. The lower boundary occurs at the relatively high mixture ratio of 2.5 , and the upper boundary occurs at 3.6.

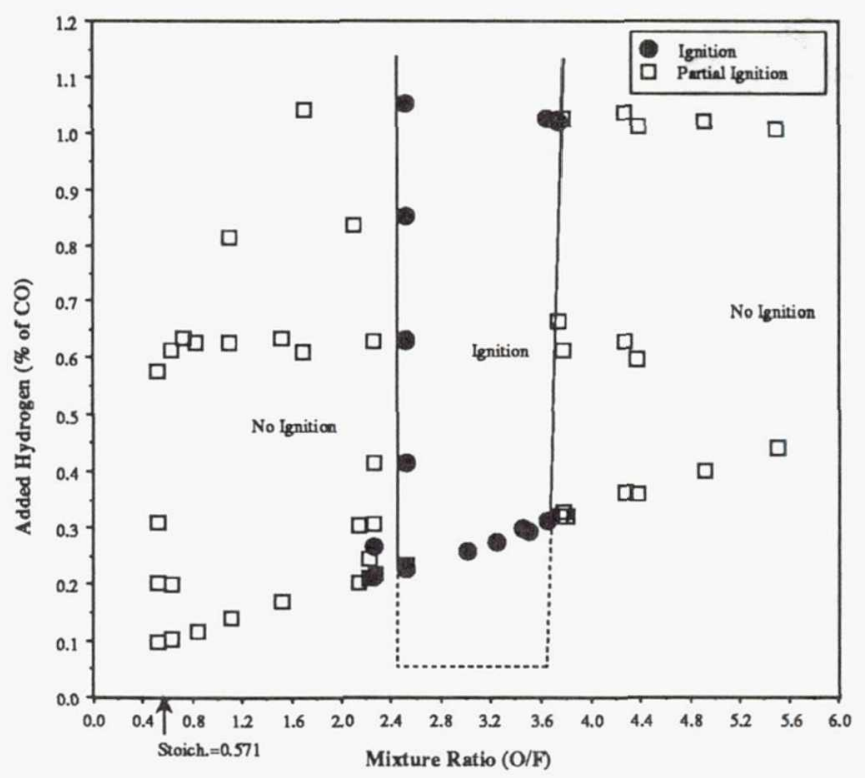

Figure 8. $\mathrm{CO} / \mathrm{O}_{2}$ Ignition Profile. Oxygen Inlet Temperature: $105 \mathrm{~K} \quad(-270$ $\left.{ }^{\circ} \mathrm{F}\right)$.

If figures 5 through 8 are examined together, it can be seen that, although the shapes of the curves exhibit similar trends, the range of mixture ratios at which ignition occurs varies from temperature to temperature. This suggests that the propellant inlet temperature has a significant effect on the ignition characteristics of carbon monoxide and oxygen.

\section{Oxygen Inlet Temperature Effects}

In order to examine the effects of temperature on ignition, the lines indicating the ignition/no-ignition boundary for each set of data were placed together on one curve for a direct comparison (fig. 9). The figure illustrates 
that the lower ignition boundary lies at a mixture ratio of approximately 0.35 for ambient oxygen temperatures, and increases with decreasing oxygen inlet temperature. The lower ignition boundary is approximately 0.40 for an inlet temperature of $255 \mathrm{~K}\left(0{ }^{\circ} \mathrm{F}\right), 0.70$ for an inlet temperature of $172 \mathrm{~K}\left(-150{ }^{\circ} \mathrm{F}\right)$, and 2.5 for an inlet temperature of $105 \mathrm{~K}\left(-270{ }^{\circ} \mathrm{F}\right)$.

Figure 9 also shows that the same trend occurs at the upper ignition boundary. That is, the upper ignition boundary is at a mixture ratio of approximately 1.5 for ambient temperatures, 2.0 for an inlet temperature of $255 \mathrm{~K}, 2.6$ for an inlet temperature of 172 $\mathrm{K}$, and 3.6 for an inlet temperature of $105 \mathrm{~K}$.

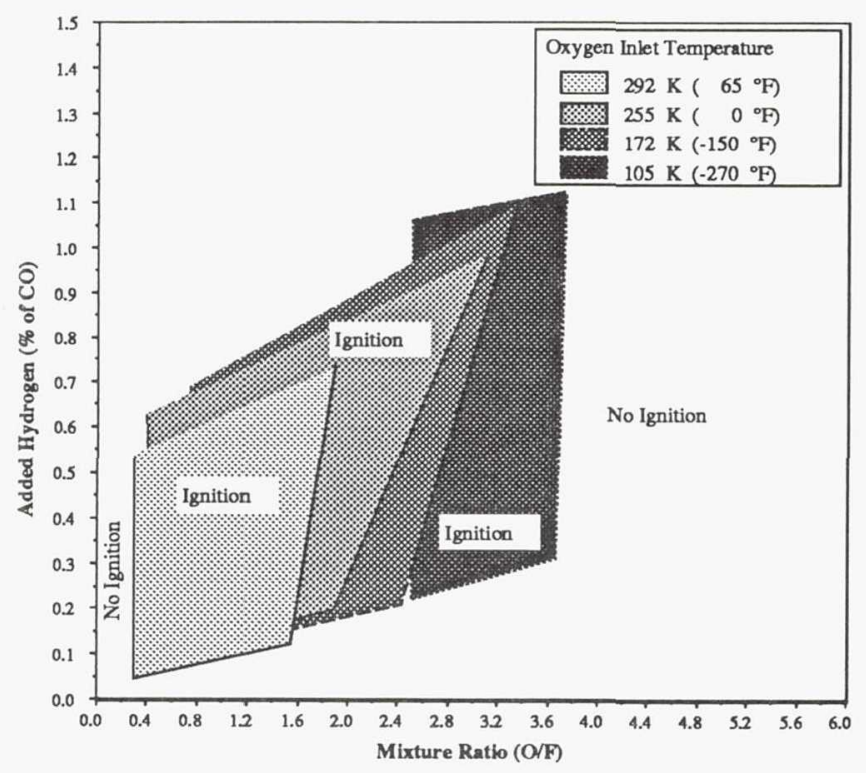

Figure 9. $\mathrm{CO}_{2} \mathrm{O}_{2}$ Ignition Profiles for Various Oxygen Inlet Temperatures.

In order to better understand the changes in the ignition profile caused by the changes in the oxygen inlet temperature, the mixture ratio was held constant at 1.3 while the oxygen inlet temperature was slowly decreased. Figure 10 shows the results from this set of tests. At a temperature greater than $120 \mathrm{~K}\left(-244^{\circ} \mathrm{F}\right)$, ignition occurred with the near minimum amount of hydrogen present (approximately 0.15 percent). As the oxygen inlet temperature was lowered from $120 \mathrm{~K}$, complete ignition was not always achieved. Finally, at an inlet temperature of $110 \mathrm{~K}\left(-262^{\circ} \mathrm{F}\right)$, no ignition was achieved with as much as 1.0 percent hydrogen in the carbon monoxide. This figure is an indication of how the decreasing oxygen inlet temperature affected the lower ignition boundary.

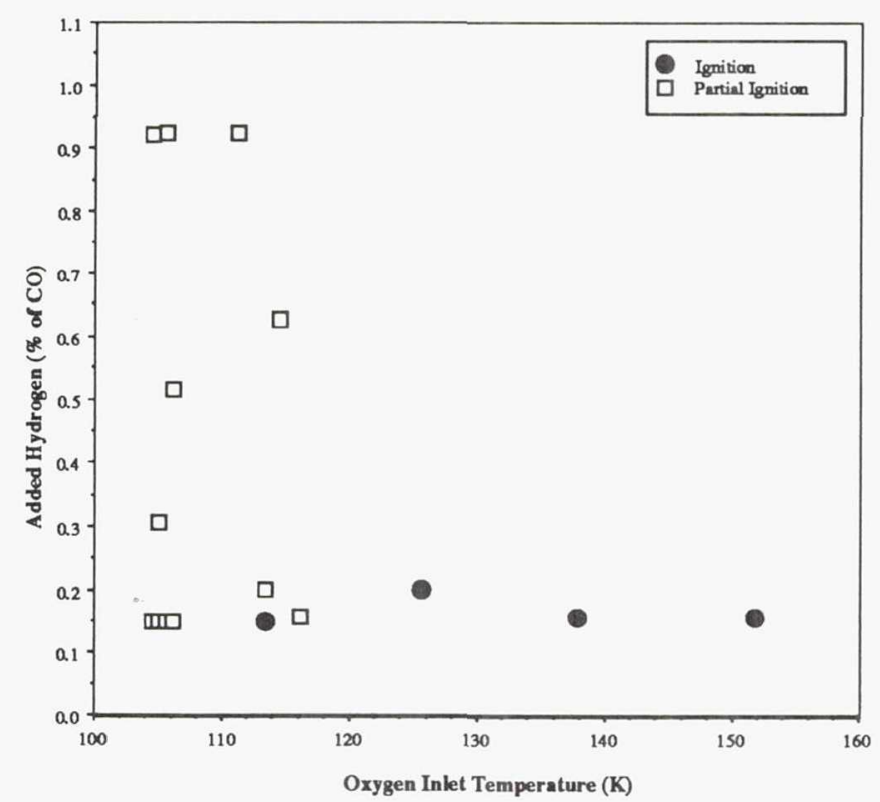

Figure 10. Effects of Oxygen Inlet Temperature on Ignition at an $\mathrm{O} / \mathrm{F}$ of 1.3 .

A similar analysis of the data was performed to investigate how the upper ignition boundary varied with oxygen inlet temperature. With the mixture ratio held constant at 2.5, the oxygen inlet temperature was slowly increased, beginning at $100 \mathrm{~K}\left(-280^{\circ} \mathrm{F}\right)$. Figure 11 shows the results from this set of tests. At a temperature of $100 \mathrm{~K}$, ignition occurred with the minimum amount of hydrogen present (approximately 0.23 percent). As the oxygen inlet temperature was increased from $100 \mathrm{~K}$, more hydrogen was needed to initiate the reaction. Finally, at an oxygen inlet temperature of $285 \mathrm{~K} \quad\left(53^{\circ} \mathrm{F}\right)$, no ignition was achieved with as much as 0.90 percent hydrogen in the carbon monoxide. This figure is an indication of how the increasing oxygen inlet temperature affected the upper ignition boundary. 


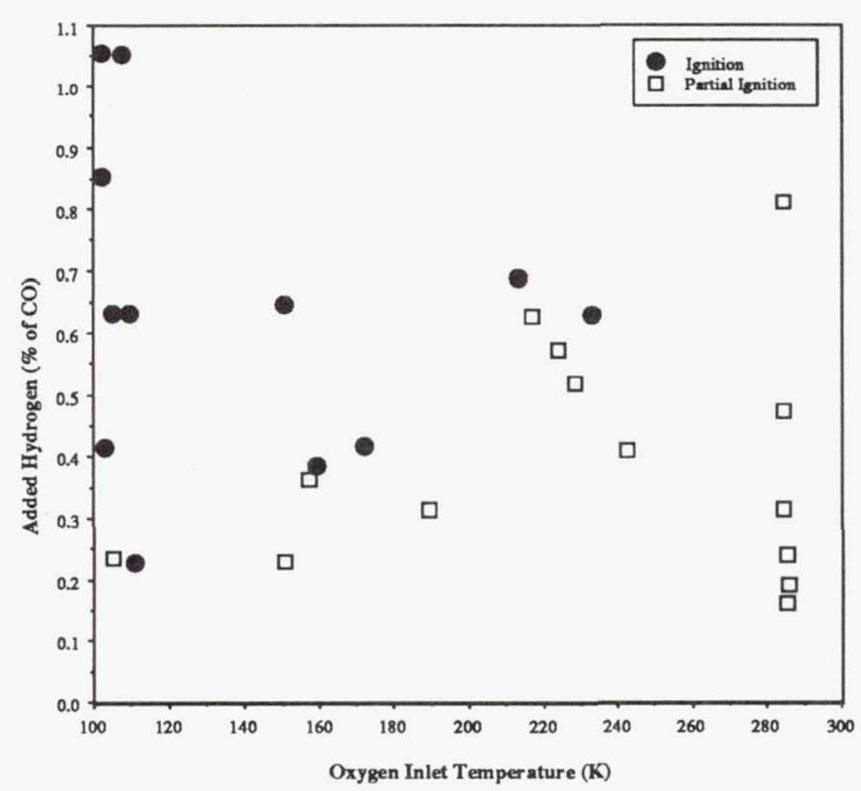

Figure 11. Effects of Oxygen Inlet Temperature on Ignition at an $\mathrm{O} / \mathrm{F}$ of 2.5 .

\section{Conclusions}

Carbon monoxide and oxygen were tested in a standard spark-torch igniter to identify the ignition characteristics and determine their suitability as a rocket propellant combination. The ignition profiles were determined as functions of mixture ratio, hydrogen content in the carbon monoxide, and oxygen inlet temperature. The following conclusions can be drawn from the experimental results.

1. Gaseous oxygen and dry gaseous carbon monoxide will not light in a spark-torch igniter. The hydrogen and water impurities in the carbon monoxide of 3.9 E-5 weight percent and 4.8 E-5 weight percent, respectively, did not provide sufficient hydrogen to initiate reaction. Ignition was achieved, however, with as little as 6.2 E-2 weight percent hydrogen in the carbon monoxide at a mixture ratio of 0.35 with ambient temperature oxygen.

2. A definite mixture ratio range exists where the carbon monoxide and oxygen will ignite and sustain after both the hydrogen and the spark are shut off. The upper boundary of this range can be extended slightly with larger amounts of hydrogen present at the start of the reaction.

3. The inlet temperature of the oxygen gas affected the ignition boundaries. Both the lower and the upper ignition boundaries shifted to higher mixture ratios with decreasing oxygen inlet temperature.

4. The oxygen inlet temperature also affected the amount of hydrogen needed at the upper ignition boundary. At lower temperatures, near minimum amounts of hydrogen were needed to achieve complete ignition. As the inlet temperature increased, more hydrogen was needed to achieve complete ignition.

The energy of the carbon monoxide and oxygen system is sufficient to sustain the combustion process in a closed system. Therefore, the key to using the carbon monoxide on Mars as an in situ fuel source is to assure that the ignition mechanism can catalyze the reaction long enough for the process to become self-sustaining. The presence of small quantities of hydrogen in the carbon monoxide should prove to be a successful method to overcome the slow kinetics of the system.

\section{Acknowledgement}

The authors would like to extend their appreciation to $\mathrm{Mr}$. Richard A. Gardin, who performed the usual miracles in maintaining and modifying the test cell, and to Mr. Gilbert M. Boyd, who performed the chemical analyses of the carbon monoxide.

\section{$\underline{\text { References }}$}

1. Hoffman, S.J., Niehoff, J.C., and Stancati, M.L., "In Situ Propellant Production: The Key to Global Surface Exploration of Mars?," AIAA-82-1477, August, 1982.

2. Sercel, J.C., Blandino, J.J., and Wood, K.L., "The Ballistic Mars Hopper: An 
Alternative Mars Mobility Concept," AIAA87-1901, June, 1987.

3. Ramohalli, K., Dowler, W., French, J., and Ash, R., "Some Aspects of Space Propulsion with Extraterrestrial Resources," Journal of Spacecraft and Rockets, Vol. 24, pp. 236-244, May, 1987.

4. French, J.R., "Rocket Propellants from Martian Resources," Journal British Interplanetary Society, Vol. 42, pp. 167-170, 1989.

5. Galecki, D.L., "In Situ Propellant Advantages for Fast Transfer to Mars," AIAA-88-2901, July, 1988.

6. Gordon, S., and McBride, F.J., "Computer Program for Calculation of Complex Chemical Equilibrium Compositions, Rocket Performance, Incident and Reflected Shocks, and Chapman-Jouguet Detonations," NASA SP-273, March, 1976.

7. Bittker, D.A., and Scullin, V.J., "GCKP84-General Chemical Kinetics Code for Gas-Phase Flow and Batch Processes Including Heat Transfer Effects," NASA TP2320, September, 1984.

8. Brown, T.L., and LeMay, H.E., Chemistry, The Central Science, Third Edition, Prentice-Hall, Inc., New Jersey, 1985, pp. 430-433. 


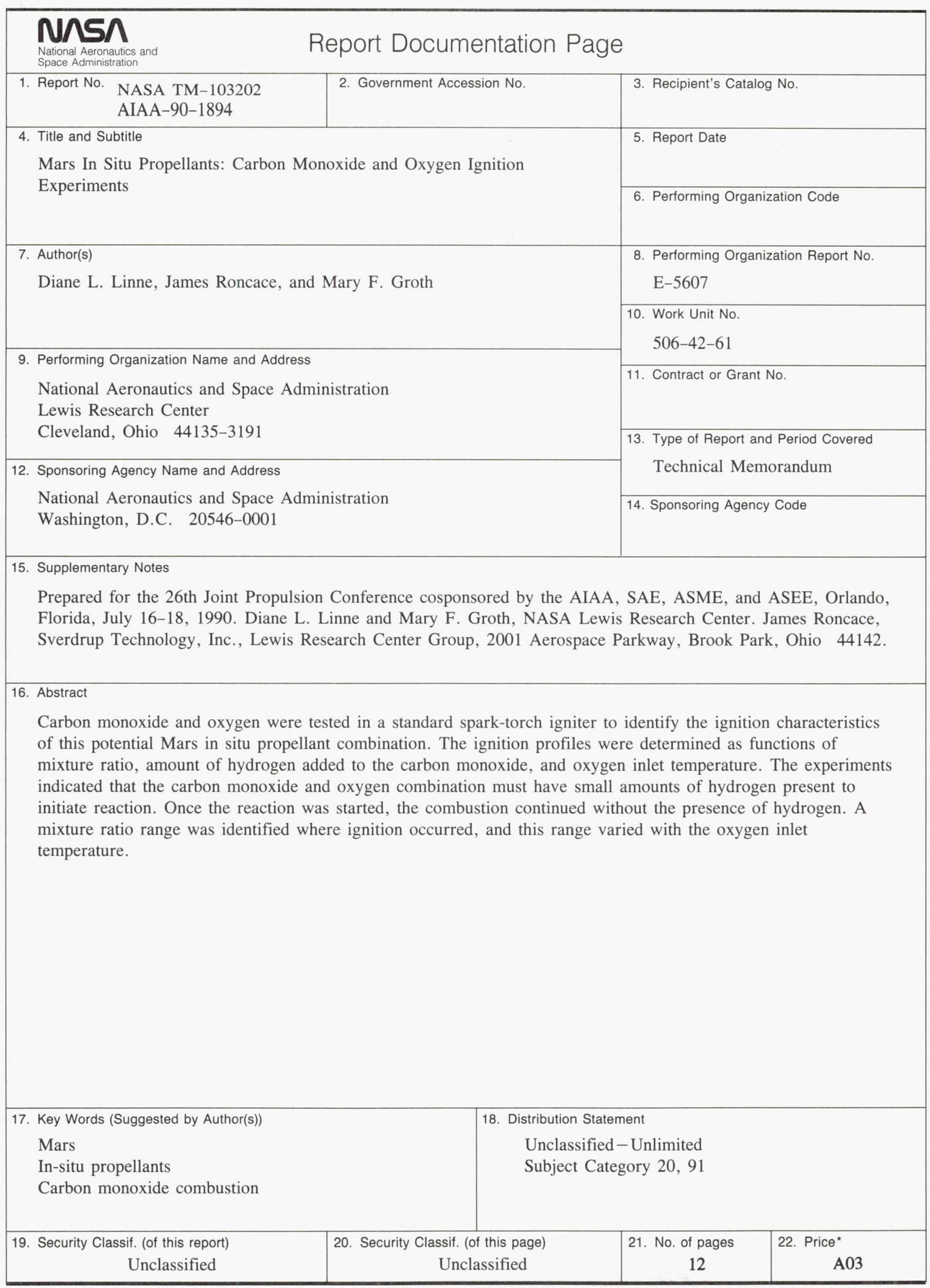

